\title{
BODY, WEB-BUILDING AND FEEDING CHARACTERISTICS OF MALES OF THE SPIDER ARANEUS DIADEMATUS (ARANEAE: ARANEIDAE)
}

\author{
By Raymond Ramousse* \\ Division of Research \\ North Carolina Department of Mental Health \\ P. O. Box 7532 \\ Raleigh, North Carolina 276I I
}

\section{INTRODUCTION}

Many investigators have observed female orb-web spiders in their natural habitats (Enders, 1972; Eberhard, 1971), but there have been relatively few scientific observations of males outdoors. A major reason for this is because after maturation males discontinue webbuilding and they seek mates and are difficult to follow in an unconfined setting. Males have also attracted less attention in laboratory situations since they have shorter life spans than females and because they stop building webs after reaching maturity. The activity of spiders in laboratories has been observed primarily in relation to their web-building behavior (LeGuelte, I966, Witt, I963a,b), making the female a more frequent subject of study. Thus, with the exception of maturation on web-building (Witt et al., 1972), only females have been comprehensively studied.

The focus of this research is to explore the activities of the males of Araneus diadematus Clerck and their role in the female-male relationship which ultimately determines the continuity of the species. Two characteristics related to the females have already been identified as possibly playing a part in the survival of the species. These include cocoon hatching and differential maturing. Cocoons have been observed hatching at two different times for a single species of spider - presumably providing an advantageous distribution of eggproduction over a period of time (Pötzsch, 1963). Also, within a set $^{1}$ of spiderlings, different rates of maturation have been observed. Some females grow rapidly and die early while others grow slowly

\footnotetext{
*Present address of author: Laboratoire d'Ethologie experimentale, 1 rue Raulin, 69 Lyon 7e, France Manuscript received by the editor March 26, 1973

${ }^{1}$ To avoid confusion with the designation of "family" used in nomenclature, offsprings from a single cocoon will be called a "set."
} 
and live at least four months longer (Reed \& Witt, 1972). The related differential maturing rates may provide an advantageous distribution of spiderlings over a period of time. Together, these mechanisms would seem to help a species survive drastic or potentially destructive changes in environmental conditions. This research seeks to explore the male's role in these phenomena. At what rate is he growing, maturing and dying during the female's life cycle?

This leads to the question of inbreeding. An observation of the maturation rates of spiderlings of the same set was conducted in an effort to determine if inbreeding is possible.

Also, if the rate of growth is a factor in the rate of maturation (and spiders of the same set are known to present a considerable variation in size even under apparently optimal conditions), (Witt et al., 1968), is growth prenatally or genetically determined or a function of external factors?

The effects of an even diet independent of manifest behavior (Witt et al., I972) and differential force-feeding on various schedules (Benforado \& Kistler, 1972) have already been studied. What, however, would happen to the growth rate of male and female spiders if they could choose their food quantity through web-building frequency?

The answers to some of these questions about the growth and maturation of male spiders should provide clues about their role in the reproductive cycle and, more generally, about their role in the continuity of the species.

\section{METHODS}

Two Araneus diadematus cocoons collected in the field, were placed in two different rearing boxes in the laboratory, where they hatched (February 23, I972, one cocoon and I4 days later, March 6, 1972, the other). The offspring from the first cocoon will be called set I, and the offspring from the second cocoon, set II. The laboratory provided a cycle of long warm days and short cool nights throughout the lifespan of the animals.

As the animals left the communal web to build individual webs, they were put in glass tubes. Five weeks after hatching for set I and three weeks after hatching for set II the spiderlings were caged in individual labeled frames $(50 \times 50 \times$ ro $\mathrm{cm}$ ) where they could build webs without apparent limitation in size. All observations began at this moment; however, some molts were noticed inside the cocoon, and the spiderlings molted one or two times in the glass tubes. 
In the rearing boxes as well as in the glass tubes they were provided water and gnats ad libitum. In the frames the spiderlings were fed with de-winged houseflies. A weighed fly was given one time every three days only when a web had been built, thus rewarding the spiders for high frequency of building.

The individual weights of the spiders (accuracy O.I $\mathrm{mg}$ ) were recorded every week and web-building was recorded every day. Each web was photographed then collapsed by the experimenter, and analyzed for size, shape, fine structure and regularity (Reed et al., I965). The dates of the molts of each spiderling were recorded and the length of the first leg was measured on the molted limb (accuracy in $\mathrm{mm}$.).

In the following pages the initials $\mathrm{FG}$ and $\mathrm{SG}$ are used in place of fast growing males and slow growing males. Statistical comparison between the two groups (SG \& FG) where not specifically mentioned was made with the Wilcoxon test, adapted by White for unpaired measurements (White, I952).

\section{RESULTS}

Of 3 I spiderlings that reached maturity in set $I$, twelve were identified as males. There were I 4 males out of a total of 29 animals in set II. The number of males in each set is significantly representative of the expected $50 \%$ probability of males in a population (Binomial test, $\mathrm{p}=0.0 \mathrm{I}$ in each case).

\section{Some characteristics of the male}

The adult males of Araneus diadematus have enlarged black palps, relatively narrow elongated abdomens, and weigh about a fifth of the adult females. Adult females are characterized by long yellow palps and a globulous abdomen (Figure I). Other characteristics of the males include banding of the legs that is generally darker, a lack of humps on the abdomen, and a modified second tibia that is stronger than in females and has short spines (Levi, I97I).

The enlarged palps appear at the end of the next-to-the-last molt, whitish instead of black, and blacken between the two last molts. One animal exhibited enlarged palps prematurely two molts before the last one and four other animals after the last molt, but these were exceptions.

After the last molt, when they reached sexual maturity and maximum weight, the males stopped building webs. Sekiguchi (1955) reported that a male of Araneus ventricosus, in the laboratory, did 


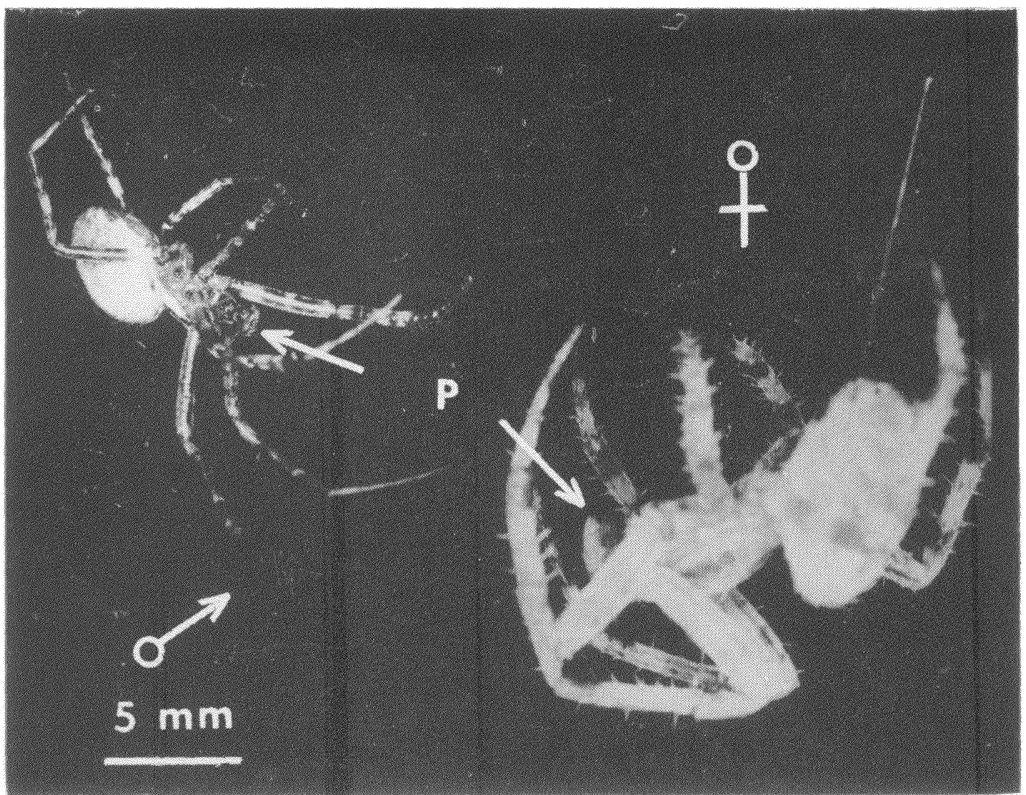

Figure 1. Outline of a male (left) and a female (right). Note the difference of size (female front leg: $16 \mathrm{~mm}$, male front leg: $12 \mathrm{~mm}$ ), of weight (female: $144.1 \mathrm{mg}$, male: $47.0 \mathrm{mg}$ ) and the difference of form of the palps (short and enlarged for the male, long and thin for the female).

not spin a web after its last molt, and that the aggregate glands become vestigial in the adult males. Prior to this point the involvement of the aggregate glands in the formation of the catching area of a web was clearly shown (Peakall, ig64). We may suppose that adult males are unable to spin webs because their aggregate glands are no longer functional.

The males ate scarcely, even when we attempted to induce prey catching by placing the flies in front of their mouths. While an immature male transformed a fly into a small compact ball through eating; the different parts of the body of a fly abandoned after eating by a mature male were easily recognizable. Even when they ate, the mature males used only a small amount of the food available. Males of Linyphia triangularis Clerck did not require food in the adult stage, and were still able to mate with females that later produced fertile eggs. When these males were provided with food, the rate of prey capture and the rate of food consumption dropped sharply 


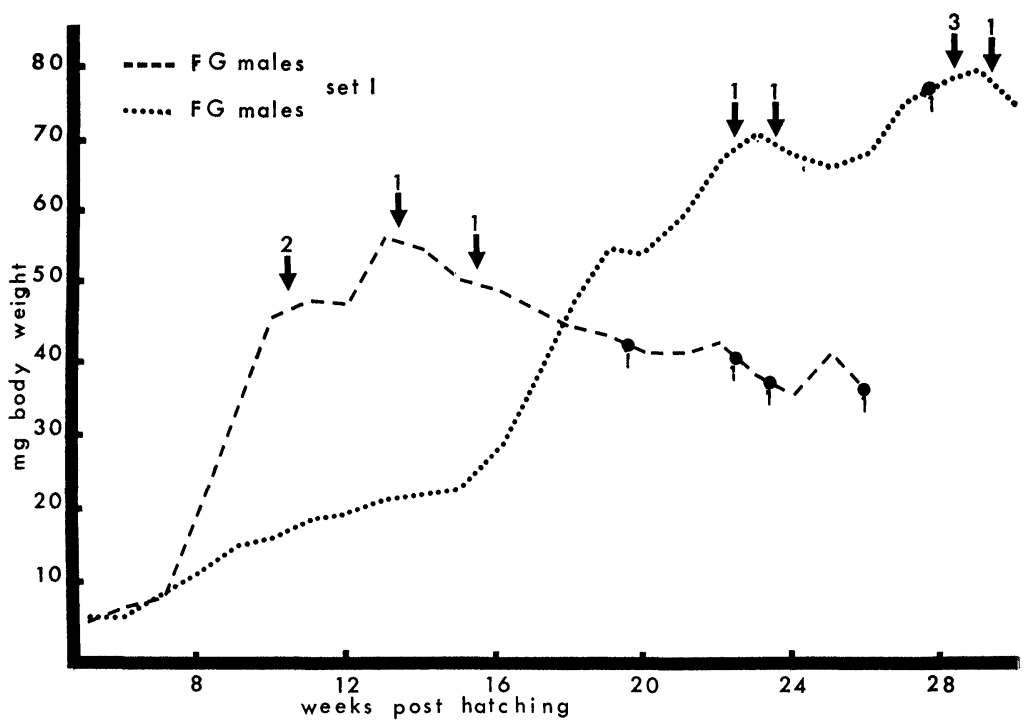

Figure 2. Body weight of four FG and seven SG littermate males in set I of Araneus diadematus, hatched in the laboratory from one cocoon on February 23, 1972. Dashed line: weekly mean body weights of the FG males. Dotted line: weekly mean body weights of the SG males. Numerals followed by an arrow indicate the number of animals molting for the last time during a week. Numerals surmounted on black circles indicate the number of animals dying during a week. The FG males reached their maximum weight the 13th week of post-hatching, the SG males reached their maximum the 29th week of post-hatching. Note that the SG animals need twice as much time to mature as the FG.

(Turnbull, I962). We may assume that the adult males, no longer able to build a web, do not neeed food to fulfill their mating role.

Four males in this study continued to spin webs until they died; they built webs for a few days after the last molt was recorded, then stopped building for three or four weeks and generally built a final web six or seven days before death. These facts suggest that these four males were not able to go through an additional molt to complete their development. Also, these males presented enlarged palps only after the last molt recorded which is another confirmation of thir inability to complete their development.

During the web building period the males are distinct from the females only between the two last molts (about 3 weeks). This explains why few studies have been made of the males either outdoors or in the laboratory. 


\section{Weight increase}

In each set, the individual weight curves follow two distinct patterns and no in between: a group with an early maximum (FG) and a group with a late maximum (SG). In set I the course of the growth of four males with early maxima (between Ioth and I5th week post hatching) was compared to seven males with late maxima (between 22nd and 33rd week post hatching) (Figure 2). In the second set the growth of I I males which reached their maximum weight between the 8 th and 16 th week post hatching was compared to three males reaching their maximum weight between the Igth and 23rd week post hatching (Figure 4). In both sets the SG animals needed approximately twice as much time to complete the last molt and to attain sexual maturity as did the FG animals. In each set the females could be divided into fast and slow growth groups in the same way as males. Figure 6 shows the body weight of the FG and SG males and females. The data from the two sets were combined forming four groups: FG and SG males and females. The weight gain per day until maturation, in both sets, was significantly higher for the FG males than for the SG males (set I: $\mathrm{T}=6, \mathrm{P}=0.05$; set II : $\mathrm{T}=7, \mathrm{P}=0.05$ ).

The mean weight gain per day between the two last molts for each group was:

\begin{tabular}{|c|c|c|}
\multicolumn{1}{c}{ set I } & set II \\
\hline FG & $2.09 \mathrm{mg} / \mathrm{d}$ & $\mathrm{I} .59 \mathrm{mg} / \mathrm{d}$ \\
\hline SG & $0.64 \mathrm{mg} / \mathrm{d}$ & I.6I mg/d \\
\hline
\end{tabular}

In each set, every animal showed a weight gain per day significantly higher between the two last molts than during the preceding period of observation (Wilcoxon matched-pairs signed ranks test: set I: $\mathrm{N}=9, \mathrm{~T}=3, \mathrm{P}=0.02$; set II $: \mathrm{N}=\mathrm{r} 3, \mathrm{~T}=\mathrm{o}, \mathrm{P}=\mathrm{o.OI}$ ).

\section{Frequency of building}

The mean of webs built per day to reach the last molt were:

$$
\text { set I set II }
$$

\begin{tabular}{|c|c|c|}
\hline FG & 0.57 web/day & 0.49 web/day \\
\hline SG & 0.22 web/day & 0.18 web/day \\
\hline
\end{tabular}


The FG males had a higher rate of building while they grew than did the SG males (set I: $\mathrm{T}=6, \mathrm{P}=0.05$; set II: $\mathrm{T}=6$, $\mathrm{P}=$ o.or $)$. The differences in the rate of building appear clearly on the graphs (Figs. 3 and 5) obtained by plotting the mean frequency of building per week for each group in each set.

The frequency of building is strongly correlated with the amount of food eaten per day (Kendall rank coefficient; set I: $\gamma=0.59$, $\mathrm{P}=0.004$; set II : $\gamma=0.52, \mathrm{P}=0.005)$. This is the necessary consequence of the feeding schedule. We might suppose that this relation occurs in nature. A fresh snare probably increases the chances of capturing prey.

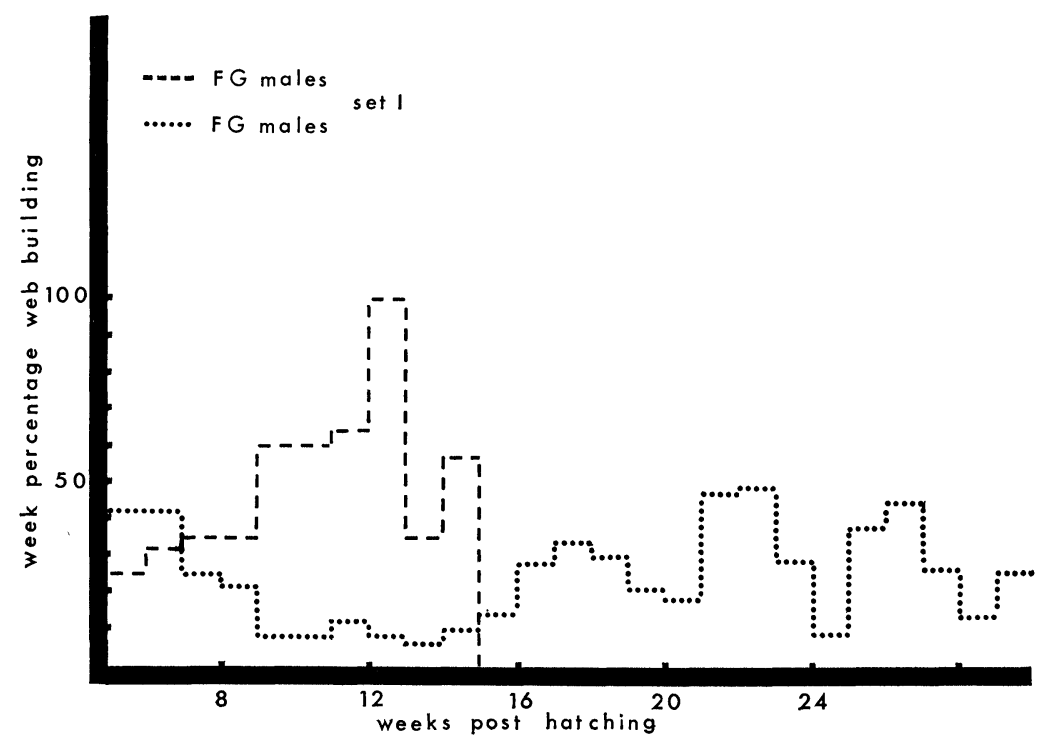

Figure 3. Frequency of building of the FG and SG males of set $I$. Dashed line: weekly mean of frequency of building for the four FG males. Dotted line: weekly mean of frequency of building for the seven SG males. Note the similarity in the pattern between weight increase and web building frequency. (Compare with Fig. 2.) 


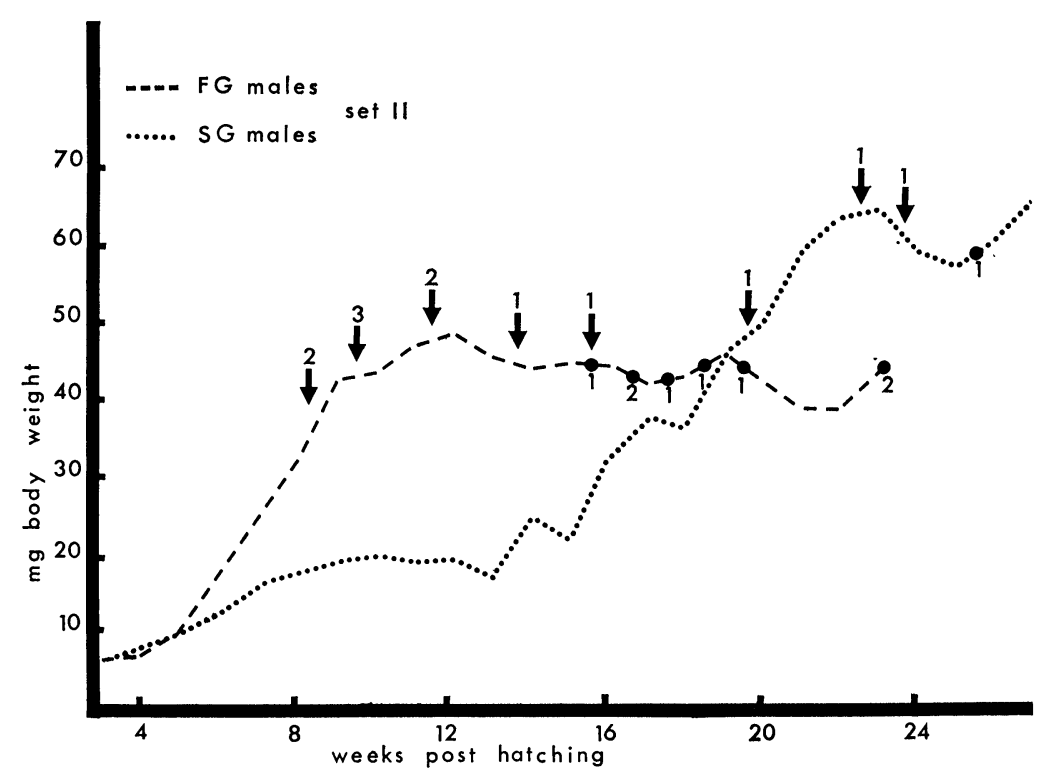

Figure 4. Body weight of 14 male littermates in set II of Araneus diadematus hatched in the laboratory on March 6, 1972. Dashed line: weekly mean body weight for the 11 FG males. Dotted line: weekly mean body weight for the three SG males. Numerals followed by an arrow indicate the number of animals molting for the last time during a week. The FG animals reached their maximum weight the 12th week post-hatching, the SG males reached their maximum the 27 th week post-hatching, when the FG males are dead. (Compare with Fig. 2.)

The rate of building:

set I set II

\begin{tabular}{|c|c|c|}
\hline FG & $0.57 \mathrm{w} / \mathrm{d}$ & $0.64 \mathrm{w} / \mathrm{d}$ \\
\hline SG & $0.3 \mathrm{I} \mathrm{w} / \mathrm{d}$ & $0.30 \mathrm{w} / \mathrm{d}$ \\
\hline
\end{tabular}

between the two last molts was significantly higher than the rate of building during the previous stages of growth in both sets (set I: $\mathrm{N}=9, \mathrm{~T}=2, \mathrm{P}=0.0 \mathrm{I}$; set $\mathrm{II}: \mathrm{N}=\mathrm{I} 2, \mathrm{~T}=\mathrm{I} .5, \mathrm{P}=\mathrm{o.OI}$ Wilcoxon test).

What explanations are there for differences in frequency of building? A multiplicity of factors have been found to have some influences on web-building: a change from dark to light, a steep rise 


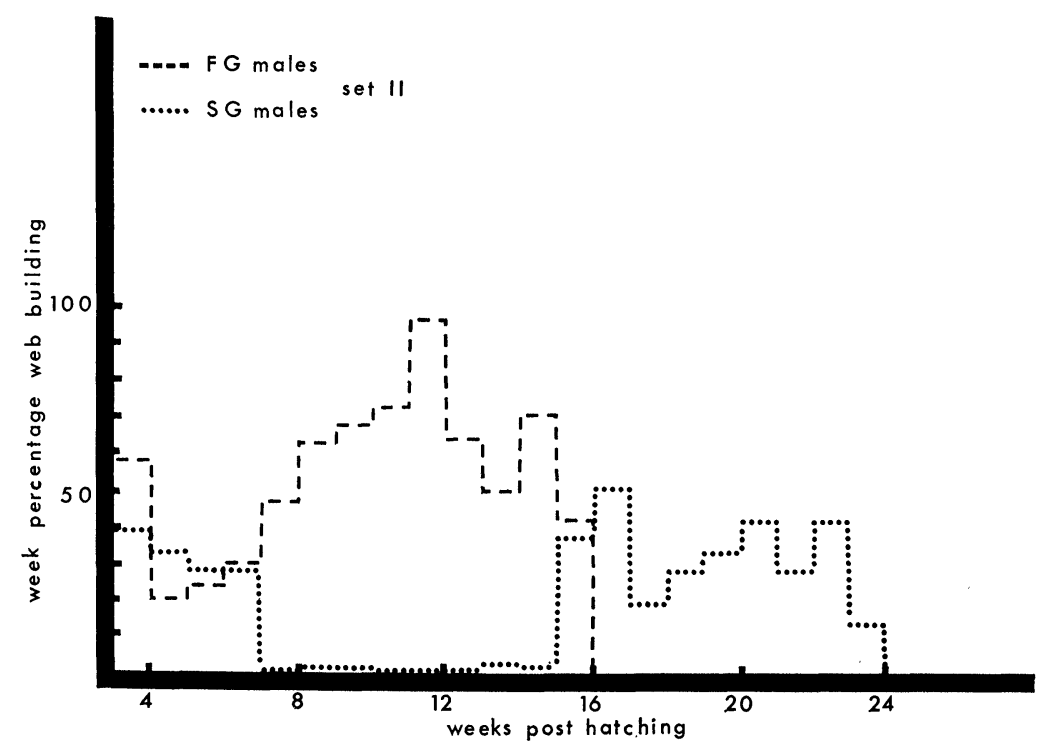

Figure 5. Frequency of building of the FG and SG males of set II. Dashed line: weekly mean frequency of building for the 11 FG males. Dotted line: weekly mean frequency of building for the three SG males. Note similarity to Fig. 3.

in temperature following a temperature minimum, weather conditions, barometric pressure, a full silk supply, hunger (Witt, et al., 1968). In the laboratory, all the spiders were subjected to the same environmental conditions, therefore the differences in rate of building should be due to an internal state, such as hunger. There is a general agreement in the literature that hunger is a strong drive for web-building. Heavy feeding is followed by several days without web-building (Koenig, 1951; Wolf \& Hempel, I95 I ; Wiehle, I927; Peters, I932). The interpretation is that the hunger drive is too low for releasers like temperature and light to operate. On the other hand, spiders deprived of food built almost every day (Peters, 1939) and built webs even at the expense of other body constituents (Witt, I963b). We may assume that the FG males have a higher level of hunger than the SG males, which induces a higher rate of building.

\section{Frood consumption}

Each time a spider was fed, the fly was weighed before eating. Since only one or two percent of a fly was rejected by a spider after 
eating, we assume that a fly was eaten entirely. The mean quantity of food consumed per day was:

set I

\begin{tabular}{c|c|c|}
\hline FG & $2.44 \mathrm{mg} / \mathrm{d}$ & $2.06 \mathrm{mg} / \mathrm{d}$ \\
\hline $\mathrm{SG}$ & $\mathrm{I} .44 \mathrm{mg} / \mathrm{d}$ & $1.39 \mathrm{mg} / \mathrm{d}$ \\
\hline
\end{tabular}

The FG spiders ate a significantly higher quantity of food per day than the SG ones (set I: $\mathrm{T}=6, \mathrm{P}=0.05$; set II: $\mathrm{T}=8$, $\mathrm{P}=0.05)$. There was a significant difference in the amount of food consumed per day between $F G$ males of the two sets $(T=8.5$, $\mathrm{P}=0.05$ ).

The mean quantity of food eaten between the last two molts was:

set I

set II

\begin{tabular}{|c|c|c|}
\hline FG & $3.33 \mathrm{mg} / \mathrm{d}$ & $2.6 \mathrm{Img} / \mathrm{d}$ \\
\hline $\mathrm{SG}$ & $2.85 \mathrm{mg} / \mathrm{d}$ & $3.54 \mathrm{mg} / \mathrm{d}$ \\
\hline
\end{tabular}

In each set the mean quantity of food consumed per day between the last two molts was significantly higher than the mean amount of food eaten per day during the preceding observation period, (Wilcoxon test: set I: $\mathrm{N}=$ IO, $\mathrm{T}=\mathrm{o}, \mathrm{P}=0 . \mathrm{OI}$; set II: $\mathrm{N}=\mathrm{I} 3$, $\mathrm{T}=\mathrm{I}, \mathrm{P}=\mathrm{O} . \mathrm{OI}$ ).

A relationship exists between the amount of food eaten per day and the growth rate in both sets, indicating that the growth rate is a function of the amount of food consumed (Kendall rank coefficient; set I : $\gamma=0.55, \mathrm{P}=0.0 \mathrm{I}$; set II : $\gamma=0.60, \mathrm{P}=0.00 \mathrm{I})$. The foot eaten was used to sustain the basal metabolism, to make silk, and to build the body of the spiders. A rough estimate of the percentage of food transformed into spider tissues was obtained by dividing the gain of body-weight per day by the quantity of food consumed per day: the FG males used about $57 \%$ (set I) and $47 \%$ (set II) of the food they ate, while the SG males transformed only $33 \%$ (set I) or $32 \%$ (set II) of their food into spider tissues. The FG groups transformed a greater amount of food consumed into spider tissues than did the $\mathrm{SG}$ groups ( 


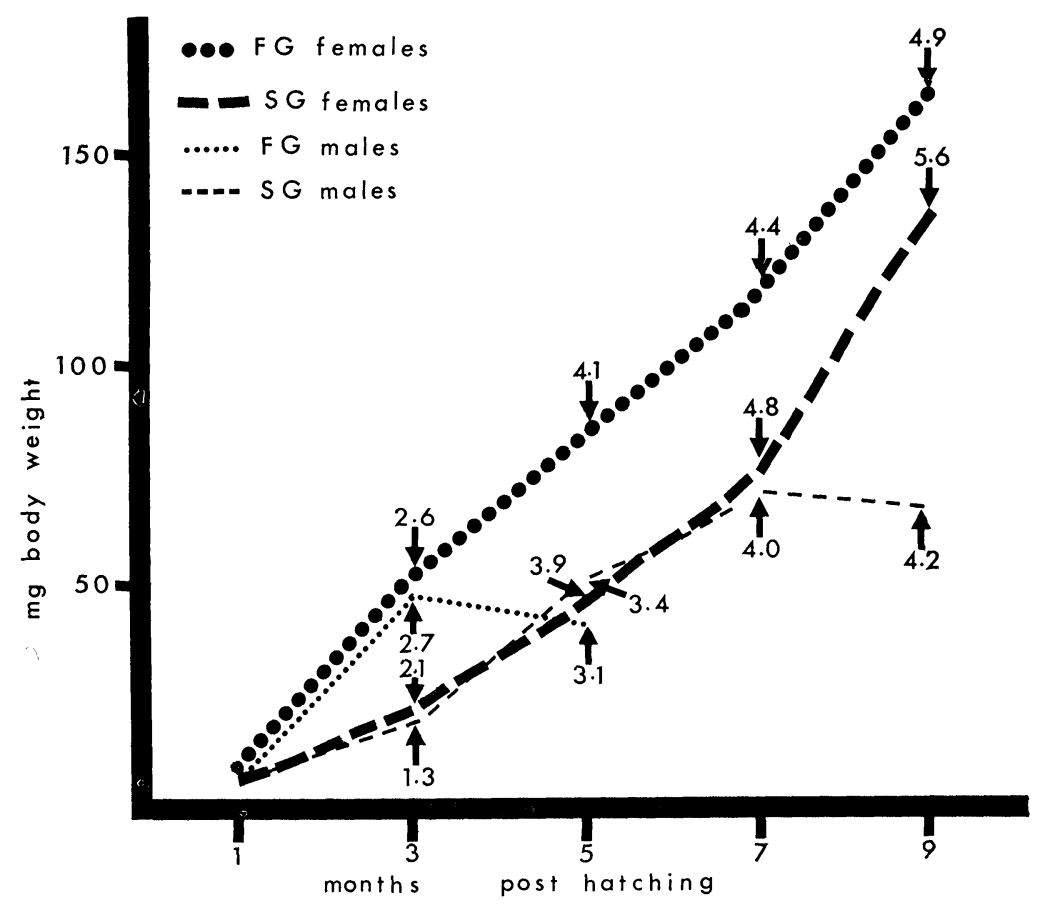

Figure 6. Body weight and number of molts of 25 males (15 FG, $10 \mathrm{SG}$ ), and 25 females (15 FG, $10 \mathrm{SG}$ ) from the two sets cocoons of Araneus diadematus studied. Each line connects mean body weights at one, two, five, seven and nine months post-hatching. Large black circles: FG females, large dashed line: early life of SG females; small black circles: FG males, small dashed line: SG males. Arrows indicate the number of molts to the time. Note the different growth rates and the related different speed of maturation in FG and SG males and females, and the similarities for both sets.

set II: $\mathrm{T}=\mathrm{I} 4, \mathrm{P}=0.05)$. As a result of having more food available for metabolism, an FG male was able to utilize more energy for other metabolic processes than basal metabolism, such as synthesis of silk, synthesis of body constituents, etc. This would assure a larger supply of silk for the FG spiders than for the SG, which could be an important drive for web-building (Peakall, I967). The increased frequency of building in the FG spiders leads to a greater amount of food consumed which in time results in the rapid weight gain and growth. 


\section{Maturation}

Between the start of the observations and the time of sexual maturity (last molt) the mean number of molts recorded for each group was:

\begin{tabular}{|c|c|c|}
\multicolumn{2}{c}{ set I } & set II \\
\hline FG & 3.25 molts & 3.27 molts \\
\hline SG & 4.50 molts & 3.66 molts \\
\hline
\end{tabular}

The SG males in set I went through a significantly higher number of molts than did the FG males $\left(\mathrm{T}={ }_{12}, \mathrm{P}=0.05\right)$ and reached a higher weight (see below). In set II, we had only three SG males and one of them did not complete its development, this explains the difficulty to obtain a significant difference between $\mathrm{SG}$ and FG animals in this set.

For set $I$ the mean time of maturation was $8 \mathrm{r} .6$ days for the FG spiders and 202.5 days for the SG spiders. In set II maturation was reached in a mean time of 78.0 days for the FG males and 163.0 days for the SG ones. The time of maturation was significantly longer for the SG animals (set I: $\mathrm{T}=6, \mathrm{P}=0.05$; set II: $\mathrm{T}=6, \mathrm{P}=0 . \mathrm{OI})$. In addition the time of maturation was significantly longer for the SG in the first set than in the second set $(\mathrm{T}=6, \mathrm{P}=0.05)$.

The rate of maturation, number of molts divided by the number of days necessary to complete these transformations, was significantly higher for the FG males than for the SG males (set I: $T=6$, $\mathrm{P}=0.0 \mathrm{I}$; set II : $\mathrm{T}=6, \mathrm{P}=0.05$ ).

The Kendall rank coefficient between the gain of weight per day and the number of molts per day was 0.6I for set I and 0.66 for set II (in both $\mathrm{P}=0.00 \mathrm{I}$ ). A relationship exists between the rate of growth and the rate of maturation which is in agreement with the findings of Deevey (1949) with Latrodectus mactans (Fabricius) and of Benforado and Kistler (1973) with Araneus diadematus. We may assume that the maturation rate is correlated with the growth rate. The mean length of time in days between two consecutive molts was determined. In 3 out of 4 groups, the last intermolt was longer than the other intermolts (table I); for the FG males, this last intermolt was significantly longer than the earlier $(\mathrm{N}=$ I0, $\mathrm{T}=\mathrm{I.5}, \mathrm{P}=0.0 \mathrm{I})$. 
Table I

\begin{tabular}{|c|c|c|c|c|c|}
\hline \multirow[b]{2}{*}{ set I } & & I & 2 & 3 & 4 \\
\hline & $\mathrm{FG}$ & 20.6 & I 4.0 & - & - \\
\hline \multirow{3}{*}{ set II } & SG & 63.3 & 37.5 & 46.1 & 29.6 \\
\hline & FG & 22.7 & I 2.0 & - & - \\
\hline & SG & 26.5 & 54.0 & 55.0 & 17.0 \\
\hline
\end{tabular}

Mean length of time in days separating two consecutive molts. The numerals designate each intermolt and its order in relation to the final one, I being the last.

Increase in leg-length

The mean length of the first leg as measured on the last molt was:

\begin{tabular}{|c|c|c|}
\hline & set I & set II \\
\hline FG & I I.0 mm & I0.5 mm \\
\hline SG & I $4.3 \mathrm{~mm}$ & $12.3 \mathrm{~mm}$ \\
\hline
\end{tabular}

SG males, which were also heavier, had significantly longer first legs than FG males after the last molt (set I: $\mathrm{T}=\mathrm{IO}, \mathrm{P}=0 . \mathrm{OI}$; set II : $\mathrm{T}=7.5, \mathrm{P}=0.05$ ).

The rate of leg growth is given by the ratio of the length gain in the number of days necessary to obtain this increase of length. The mean rate of leg growth during the entire observation was:

\begin{tabular}{|c|c|c|}
\hline \multicolumn{1}{c}{ set I } & set II \\
\hline FG & $0.183 \mathrm{~mm} / \mathrm{d}$ & $0.176 \mathrm{~mm} / \mathrm{d}$ \\
\hline $\mathrm{SG}$ & $0.069 \mathrm{~mm} / \mathrm{d}$ & $0.069 \mathrm{~mm} / \mathrm{d}$ \\
\hline
\end{tabular}

The rate of length increase was significantly higher for the FG males than for the SG males (set I: $\mathrm{T}=\mathrm{IO}, \mathrm{P}=$ o.oI; set II: $\mathrm{T}=7, \mathrm{P}=0.05)$. This points out the relationship existing between rate of maturation and rate of lengthening. No correlation was found between the leg-growth between molts and the length of time of the intermolt.

Maximum weight

Body weight increased for all males to a maximum at the last molt, declining from this point onwards. This is in contrast to 
female weight increase which continues after the last molt, possibly due to egg formation. The mean weight was:

\begin{tabular}{|c|c|c|} 
& set I & set II \\
\hline FG & $62.95 \mathrm{mg}$ & $57.64 \mathrm{mg}$ \\
\hline SG & $88.52 \mathrm{mg}$ & $70.23 \mathrm{mg}$ \\
\hline
\end{tabular}

The maximum weight reached by the FG males, in both sets, was lower than for the SG males. This suggests that the maximum weight may be a function of the duration of development. In that case, rapid maturation would occur at the expense of weight growth.

No correlation between initial weight and final weight was found in contrast to the findings of Benforado and Kistler (1972). A relatively small difference in initial weights and the low accuracy of the weights may explain the contrast.

\section{Mating}

The FG males of set I matured 8 I.6 days post-hatching (p-h.) and those of set II 78.o days $\mathrm{p}-\mathrm{h}$. The FG females reached maturity 229 days p-h. in set I and IO4 days p-h. in set II. In the first set all the FG males were dead before any of the FG females were mature, preventing them from mating. In the second set, the FG males survived 7I days after the last molt, so that some of them were still alive when the first FG females matured. But the females accepted the advances of the males only 60 days or more after the last molt, preventing the FG males from mating with their sisters. In summary, the FG males of both sets were sexually mature too early to mate with any of the females of the same set.

The SG males reached maturity 202 days $p-h$. in set $I$ and $I 63$ days $p-h$. in set II. At this time the FG females of set II were already mature ( $\mathrm{IO} 4$ days p-h.) and those of set I were almost mature (229 days p-h.), as well as the SG females of set II (223 p-h.). In these conditions the $\mathrm{SG}$ males of both sets may have been able to mate with the FG females of their own set or the other set.

Each of the nine SG males, when they were an average of 300 days p-h., were brought into the presence of three different females. All the males seemed to behave in the same way, but only three of them mated successfully with a single female, and one with two different females. These successful males were the biggest of the SG males. One male of each set was able to mate with a female of 
his own set. Only the FG females of the set I accepted the males, while both FG and SG females of set II accepted the males. However, the small number of males limited the number of trials and did not permit us to know statistically which of the females (FG or SG) were the most successful in mating.

The FG males cannot mate with females of their own set, but we may assume that they can find females of other sets in a natural habitat which are mature at the same time. The SG males can mate with the FG females of their own set, permitting limited inbreeding. This is merely a possibility since different sets in nature may have mature females at the same time.

\section{Comparison of the webs of $S G$ and FG spiders Web changes during development:}

Webs for the FG and SG males were compared on the basis of the spiral area, mesh size and thread length.

The spiral area of all webs built by males in both groups and both sets showed a general increase until reaching a maximum area during the period between the last two molts. The spiral area decreased in size thereafter. Four males mentioned earlier, who did not follow the general web-building pattern (they built webs until they died), showed no decrease in spiral area in their final webs. This further supports speculation that they died before achieving full development through a complete series of molts. In contrast, the spiral area of the females of Araneus diadematus and Neoscona vertebrata increased until the last three months, after which time the catching area does not change significantly (Witt \& Baum, 1960). The catching area of the females of the golden garden spider, Argiope aurantia, showed a growth and decline, the peak size coinciding roughly to the time of last molt and sexual maturation (Reed, Witt \& Scarboro, 1969).

An essentially upward linear growth in mesh size throughout the lifetime occurred for II of the males studied. For the I2 other males the mesh size increased until reaching a plateau during the last intermolt. Witt, Rawlings and Reed (1962) have pointed out that the mesh size of the female webs of Araneus diadematus show also an increase until the last molt, and then reach a plateau. But Argiope aurantia shows a linear growth in mesh size throughout the lifetime (Reed, Witt \& Scarboro, 1969).

The thread length follows the same pattern as the two other parameters with a peak during the last intermolt and then a decrease. Argiope aurantia and Araneus diadematus females have been shown 


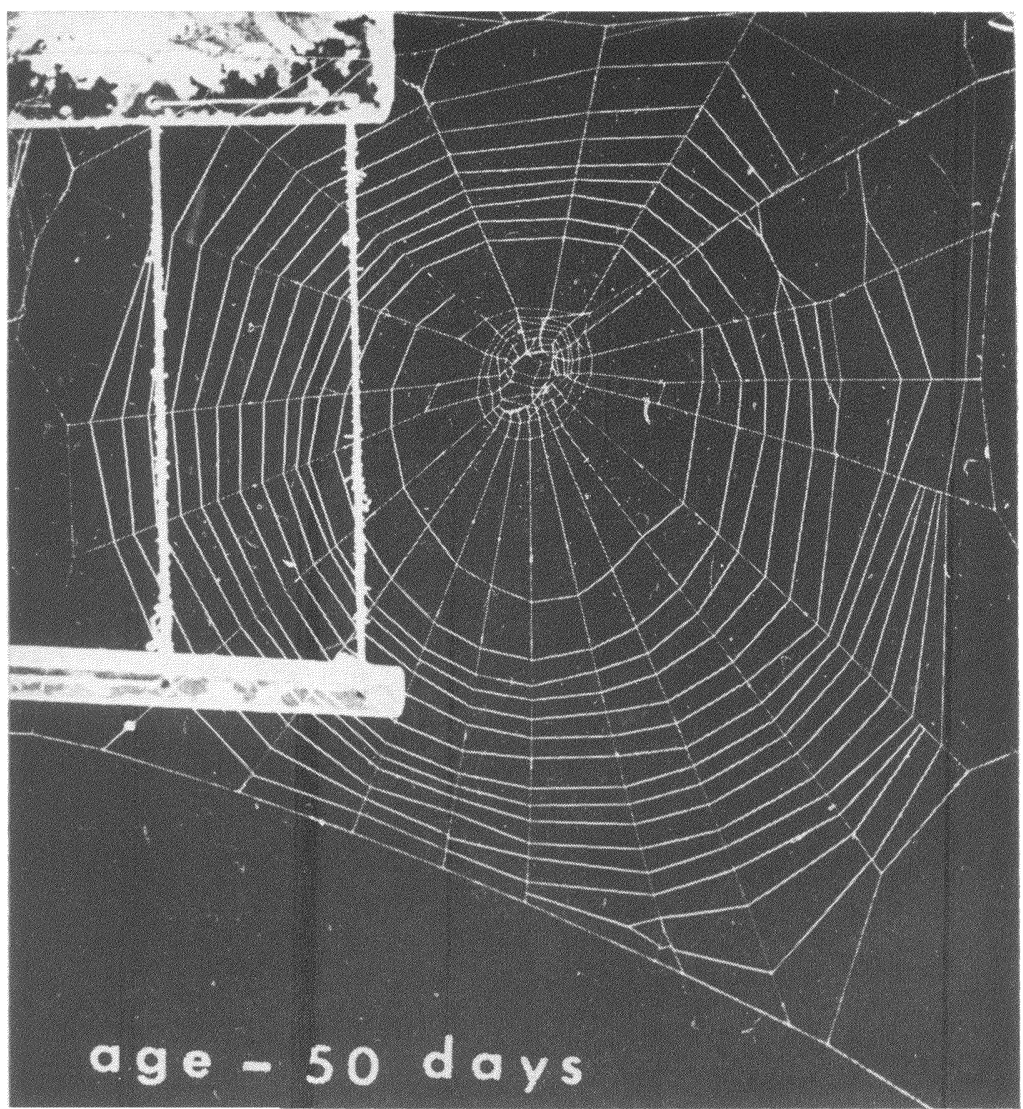

Figure 7. Web built by a young male of Araneus diadematus. Young FG and SG males built webs with the same characteristics, small and finemeshed. The vertical white lines of the scale are spaced $20 \mathrm{~mm}$ apart. 
to change according to the same pattern for thread length (Reed, Witt \& Scarboro, 1969; Witt, Rawlings \& Reed, 1972). The decrease of the thread length may be due to the thickening of the threads as the weight of the spider increases (Christiansen et al., 1962). The males follow the same pattern of web-changes as the females of the same species, except for the catching area. The general effect is that young Araneus diadematus males build small, fine-meshed webs (Fig. 7); and during the onset of the last intermolt build large, wide-meshed webs; males at the end of the last intermolt, without changing weight and leg-length significantly, build medium meshed webs. Therefore it appears that web size cannot simply be explained by the spider's bodily dimensions (Witt, Rawlings \& Reed, 1972; Reed, Witt \& Scarboro, 1969).

\section{Comparison of the webs of the FG and $S G$ males at the same age}

All the webs photographed between the 9th and I2th weeks post hatching of five FG males of both sets were measured. So were the webs of eight SG males of both sets during the same period of time. All these spiders were at the same age, but the five FG spiders were almost mature and the eight SG males were IOO days before reaching maturation. Table 2 shows the figures for spiral area, mesh size, thread length and a measure of the regularity of the spacing of the threads (standard error of median mesh size North). The two measures of the body, and the four measures of the web show significant differences between the FG and SG males, with the exception of the variance of the mesh size: the webs of the two groups show similar regularity.

Table 2

$\begin{array}{lcccl} & \text { FG } & \text { SG } & \text { t } & \text { P } \\ \text { Body weight } & 50.1 \pm 19.0 \mathrm{mg} & 22.6 \pm 6.4 \mathrm{mg} & 3.58 & 0.005 \\ \text { Leg length } & 9.1 \pm 1.70 \mathrm{~mm} & 6.68 \pm 1.48 \mathrm{~m} & 2.49 & 0.05 \\ \text { Spiral area } & 42,138 \pm 9,883 \mathrm{~mm}^{2} & 13,956 \pm 8,178 \mathrm{~mm}^{2} & 4.88 & 0.001 \\ \text { Mesh size } & 58.60 \pm 6.96 \mathrm{~mm}^{2} & 34.75 \pm 10.08 \mathrm{~mm}^{2} & 4.05 & 0.005 \\ \text { Thread length } & 16,066 \pm 4,111 \mathrm{~mm} & 6,950 \pm 3,282 \mathrm{~mm} & 4.07 & 0.005 \\ \text { SE median mesh } & & & & \\ \text { size North } & 0.114 \pm 0.030 & 0.162 \pm 0.062 & 1.47 & \\ \begin{array}{l}\text { Measures of webs of the FG and SG males at the same age. Only the } \\ \text { regularity measures in the last line are not significantly different. }\end{array}\end{array}$


Table 3

FG

$$
\text { SG }
$$

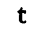

$\mathbf{P}$

Body weight

$60.14 \pm 11.56 \mathrm{mg}$

$79.37 \pm 18.07 \mathrm{mg}$

0.11

Leg size

$10.75 \pm 1.22 \mathrm{~mm}$

$13.60 \pm 1.41 \mathrm{~m}$

4.90

0.001

Spiral area

$33,931 \pm 10,131 \mathrm{~mm}^{2}$

$28,766 \pm 6,559 \mathrm{~mm}^{2}$

1.15

0.400

Thread length

$15,546 \pm 2,768 \mathrm{~mm}$

$10,425 \pm 1,715 \mathrm{~mm}$

$3.66 \quad 0.005$

Mesh size

$46.46 \pm 9.64 \mathrm{~mm}^{2}$

$70.73 \pm 15.95 \mathrm{~mm}^{2}$

3.99

SE median mesh

size

$0.900 \pm 0.022$

$0.293 \pm 0.068$

8.78

0.001

Measure of webs of the FG and SG males at comparable stage of maturity.

It is neither possible to relate the regularity measures to leg length - the FG's legs were significantly longer than the SG's legs - nor to maturation since the FG spiders were at the last stages of maturation and the SG males two or three stages before. We may assume that the size of the males' webs but not their regularity is a function of the rate of growth and in consequence of the body dimensions.

\section{Comparison of the $F G$ and $S G$ males' webs at the same stage of maturation}

All the FG webs photographed during the last stage were compared with all the SG webs photographed about Ioo days later, during their last stage; this compares webs built at different times but comparable stages of maturity. Table 3 gives the figures for body weight, leg size, spiral area, thread length, mesh size and the variance of the mesh size. The webs of the FG (lighter) males had a spiral area larger, a significantly longer thread, smaller mesh size, and a higher regularity than the webs built by the SG males at comparable maturity (Figs. 8 and 9). The longer length of thread produced by the FG males than the SG males indicates that they have a better supply of silk or thinner thread. This may be supported by the higher amount of food eaten per day and the higher rate of utilization of the food by the FG than SG males. The larger mesh size and irregularity of the SG webs is related to the larger body dimensions of these animals. The difference between the dimensions of the bodies of the FG and SG males coincides with a longer duration of development for the SG than for the FG males. We may assume that the regularity of spacing the spiral thread is related to the duration of the development in the two groups of males with different rate of growth, and is related to maturation within a group having a homogenous growth rate. 


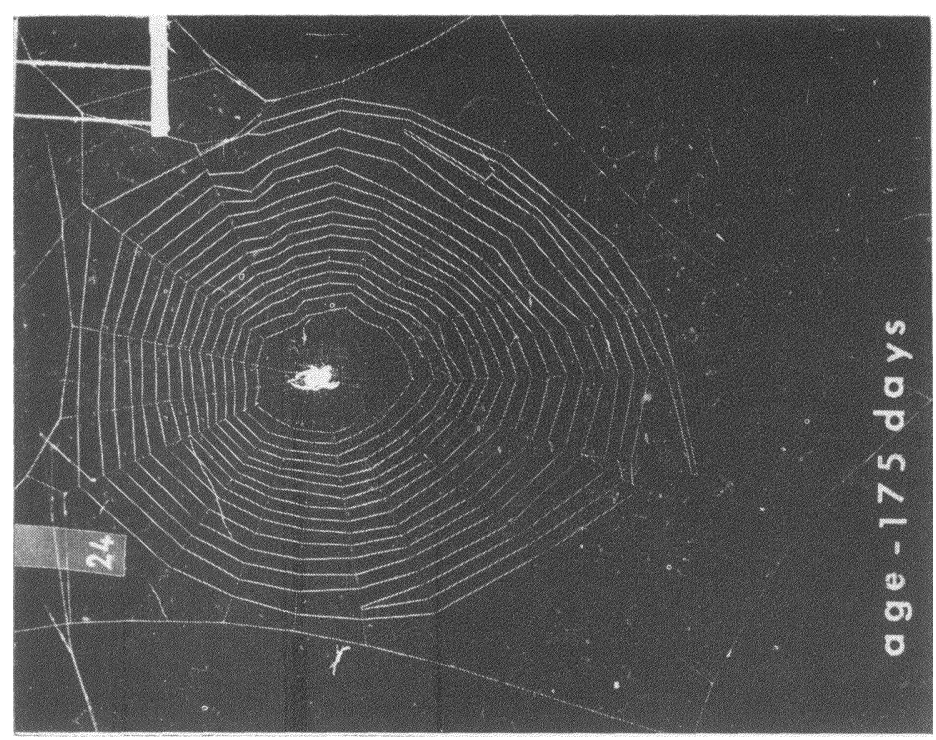

导. 氖 合苛范 논 点 है. Е ๑

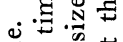
घू त

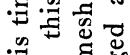
曲范栗 㟧 का ह घ을 댕 궁흥 त 운 की 80 告 .$\Xi 500$

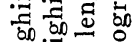
उ苛要

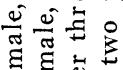

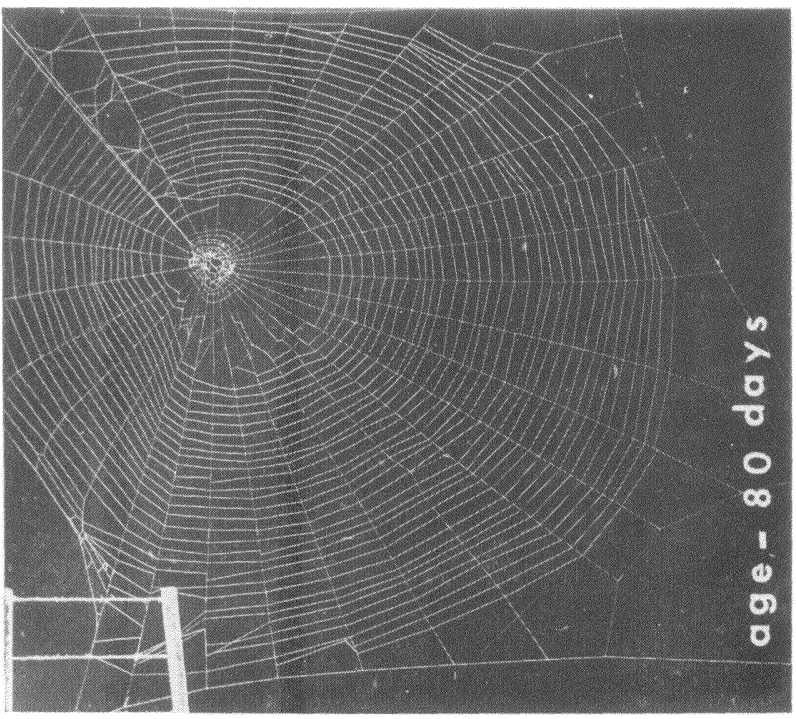

00 ○ 垴 毒告 हี ฐี घ घ 느몀 荡范焉

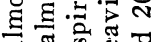
ส สิ สन कूष की

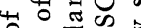
유 एँ .

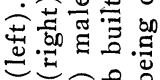
$\infty a$ 离范 돈

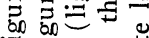

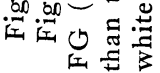




\section{Mortality}

The mean mortality in each group was:

set I

set II

\begin{tabular}{|c|c|c|}
\hline FG & $\begin{array}{c}\text { I6r.6 days post-hatching } \\
\text { SG dead (mean } 329.0 \text { days } \\
\text { post-hatching) } \\
3 \text { still living (342.0 days } \\
\text { post-hatching) }\end{array}$ & 308.6 days post-hatching \\
\hline
\end{tabular}

The SG males lived significantly longer than the FG males (set I: $\mathrm{T}=\mathrm{IO}, \mathrm{P}=0.0 \mathrm{I}$; set II: $\mathrm{T}={ }_{4}, \mathrm{P}=0.05$ ). Rapid growth occurs at the expense of endurance which is in agreement with the findings of Bonnet (1935), who found that the spiders' lives shortened with an increase in food supply, and the findings of Reed and Witt (1972), who found that the FG females of Araneus diadematus lived shorter than the SG females.

In our laboratory, the males matured from July 1972 to January 1973. But in North America males of Araneus diadematus can only be found in September and early October in the Boston area, (Levi, 1971) and in Southern France in August and September (Bonnet, 1935). Nevertheless some authors found Araneus diadematus in the field during different seasons even in winter, Bertkau ( 1885 ) in Germany and Termeyer (I79I) in Italy. Millot (1926) also obtained, in the laboratory, the survival of young Araneus diadematus during the winter; they completed their development the following spring. The biological cycle of Araneus diadematus varies according to the environmental conditions it goes through, and a low rate of feeding with the stable laboratory conditions could allow a longer lifespan for the spiders reared in the laboratory than in the field. In that case, the lengthening of the development merely emphasizes the difference betwen FG and SG animals.

The FG males survived an average of 80 days after the last molt in set I and 7I.4 days in set II. These males grew and built webs approximately half their lives, then sought out mates. We can note equivalent facts for the SG males with their relatively long time scale. 


\section{General Discussion}

The males grow until the last molt, at which time they attain their maximum weight; weight decreases slowly thereafter. The females have a distinctly different course of growth; their weight increased long after the last molt, generally until they lay a cocoon. The males mature more rapidly than the females, but the females grow bigger than the males and live longer.

The females and the males of each of the two sets of Araneus diadematus studied are clearly divided into FG and SG. The FG males are characterized by a higher frequency of building, rate of food consumption, rate of weight increase, rate of leg growth, rate of maturation as well as a smaller number of molts than the SG males, significant only for set $I$ in the last instance.

The positive correlation between the rate of building and the rate of food consumption for all males must be expected, since the spiders were fed only when they had built a web. The different frequency of building may be explained as a lower threshold for web-building through hunger in the FG than in the SG spiders. The number of prey captured is a function of behavior mechanisms of the spider and potential prey; among the former are the stimuli that induce the spider to attack, the efficiency of this attack, and also a number of other variables such as web-site, web-characteristics, and frequency of building. The hunger stimulus which induces both, the attack and web-building, has a lower threshold for the FG than for the SG spiders, suggesting that in a natural habitat the FG males would be able to capture and eat more food than the SG spiders. In addition, the usual effect of genes on animals with rigid patterns is to alter behavior in a quantitative, rather than a qualitative, fashion (Manning, 1967). The environmental conditions being the same for all the animals, the difference in threshold of hunger may be the consequence of different genotypes.

A relationship between the rate of food intake and the rate of growth indicates that the food was converted into spider tissues, in addition to maintain basal metabolism and to support the necessary activities like prey catching. The percentage of food converted into spider tissue was higher for the FG males than for the SG males, explaining the different growth rates. The same mechanism could provide a more ample supply of silk for the FG than for the SG males, which is suggested by the analysis of the web dimensions of 
the two groups. Hunger is an important drive for web-building and prey catching, which in turn increases the amount of food available to the spider. As a consequence, a good supply of food permits the spider to use more energy to metabolize tissues and silk, and a full supply of silk lowers the threshold of web-building. So, the frequency of building may be controlled by a changed feed-back between hunger and amount of food eaten.

A strong relationship exists between the rate of growth and the rate of maturation. But the number of molts was not constant, nor was the time separating two successive molts. The FG males went through fewer stages than the SG males (significant only in set I) and in less time. The rapid increase of the body weight of the FG spiders seems to force these spiders to change more often their rigid skins. Ecdysis is a crisis that requires extra energy to overcome; the heavy eating FG spiders could accumulate this extra energy in the form of reserves more rapidly than the SG spiders. The differential maturation may be attributed to nutrition. But nutrition is a function of the amount of food eaten controlled through appetite, proficiency in prey-catching, and web-building frequency. Similar relations must explain the differences in development between males and females as well as between females of the same set.

Different schedules of feeding result in differential growth and maturation for spiders of the same set (Benforado and Kistler, 1972), suggesting that the amount of food eaten is a determinant factor. But with the same amount of food available, the spiders of the same set show different growth rates and maturation rates (Reed \& Witt, I972). This indicates that prenatal or genetic conditions control the development and maturation. In our study, the spiders could choose the food quantity they need through their behavior. When the spiders are in identical environmental conditions, we may assume that the difference in behavioral patterns present at hatching time probably are genetically determined. One pattern induces some spiders (FG) to capture and eat more food than other spiders, and in turn this large amount of food eaten by these spiders, increases their rate of development and maturation. The rapid growth in the two sets occurs at the expense of endurance and maybe weight increase, the FG males are short livers and small weighers. The short life-span of the FG spiders prevent them from mating with females of the same set, while some SG males live 'ong enough to mate with the FG females of their own set. 
Poetsch has shown (1963), that cocoons of a single species of spider hatch at different times. This presumably provides an advantageous distribution of egg-production over a period of time. The two cocoons studied hatched at different times, and the males of set II, which hatched fifteen days later, grew faster than the males of set I (significant only for the SG males). Between the sets the rapid growth occurs also at the expense of endurance and maybe weight increase. Differential growth occurs between the sets as well as within the sets, favoring the distribution of mature animals over a period of time. This suggests that during the favorable season mature males and females can mate and produce cocoons at various times, providing the species with a better chance to survive any drastic crisis due to the environment.

The relative quick maturation of males favors mating between animals of different sets and of different behavior instead of inbreeding. This allows the species to conserve a genetic pool with high selective potentialities, Dobshansky, I95 I).

During development the last intermolt was distinct from the other stages. During this period the males built more webs, ate more food per day, and grew faster than during the other stages. The time separating the last two molts was generally longer than the time separating any other two successive molts. Sexual differentiation also took place during this period, and we may assume gametogenesis too. This would explain why the males need more food and a longer time to complete the last stage of development. The importance of the requirements during this time must make it the most difficult for the males.

\section{Summary}

The offsprings from two cocoons of Araneus diadematus, hatched at different times and placed in individual frames, were studied in the laboratory during the life-span of the males. During this time, the characteristics of the body (weight and size), the frequency and the parameters of the webs, the number and date of the molts, and the amount of food eaten were recorded for each animal. The spiders could choose their feeding schedules through their building behavior.

The males built and increased their weight only until the last molt, in contrast to the females which continued both building and increasing their weight long after the last molt. During the 
building period the males were distinctly different from the females only during the last stage. The males lived shorter and grew less than the females. The last intermolt was distinct from the other stages: the males built more webs, ate more food, grew faster than during the other stages.

Two different rates of development appeared among the males of each set, determining a fast and slow growing group. The frequency, the amount of food eaten, the rate of weight increase and the rate of maturation were higher for the fast growers than for the slow growers. As a consequence of the rapid growth, the life-span of the fast growing males was shorter and the maximum weight was lower (but not significantly) than for the slow growing males. Hunger and amount of food eaten determined the different growth rates and related maturation rates; a lower threshold is supposed for the fast growing males than for the slow growing males, and may be the consequence of a genetic difference. Maturation would be controlled by different patterns of behavior determined on a genetic level.

The differential maturation, which occurs within animals of a set and between sets, results in a distribution of mature animals over various times of year. The relative quick maturation prevents the fast growing males from mating with a female of the same set, but limited inbreeding is possible between the slow growing males and the females of the same set. A potential high survival of the species is assured by the dispersion of the individuals of one set and the dispersion of the sets over different seasons.

\section{ACKNOWLEDGEMENTS}

This work was carried out in the laboratories of the Division of Research, North Carolina Department of Mental Health and was supported by Grant Number GB-25274 from the National Science Foundation to Dr. Peter N. Witt. The author gratefully acknowledges the assistance of Dr. Witt during all stages, the assistance of Mrs. Mabel Scarboro for all technical and laboratory work, Mrs. Rubenia Daniels for her administrative assistance, and of Dr. John O. Rawlings with whom the statistical tests used were discussed.

\section{REFERENCES CITED}

BENFORAdo, J. AND Kistler, K. H.

1973. Growth of the orb weaver, Araneus diadematus, and correlation with web measurements. Psyche, 80: 90-100. 
Bertkau, $\mathrm{Ph}$.

1885. Ueber den Saisondimorphismus und einige andere Lebenserscheinungen bei Spinnen. Zool. Anz. 8: 459-464.

BONNET, P.

1935. La longévité chez les Araignées. Bull. Soc. Etomol. de France. $40: 272-277$.

Christiansen, A., Baum, R. and Witt, P. N.

1962. Changes in spider webs brought about by mescaline, psilocybin and an increase in body weight. J. Pharmac. ex. Ther. 136: 31-37.

DEEVEY, G. B.

1949. The developmental history of Latrodectus mactans (Fabr.) at different rates of feeding. Amer. Midl. Nat. Notre Dame, 42: 189-219.

DoBzhanskY, $T$.

1951. Genetics and the origin of species. Columbia University Press. EBERHARD, W. G.

1971. The ecology of the web of Uloborus diversus (Aranea: UloboriENDERS, R. dae). Oecologia (Berlin), 6:328-342.

1972. Web site selection by Argiope aurantia Lucas and other orb weaving spiders (Araneidae). Thesis, N. C. State University, Raleigh.

Koenig, M.

1951. Beiträge zur Kenntnis des Netzbaus orbiteler Spinnen. Z. Tierpsychol. $8: 462-493$.

LeGuelte, L.

1966. Structure de la Toile de Zygiella-x-notata $\mathrm{Cl}$. (araignées, Agriopidae) et quelques facteurs qui régissent le comportement de l'araignée pendant la construction de la toile. Thèse, Nancy.

LEVI, H. W.

1971. The diadematus group of the orb-weaver genus Araneus north of Mexico (Araneae: Araneidae), Bull. Mus. Comp. Zool., 141 (4) : 131-179.

Manning, A.

1967. Genes and the evolution of insect behavior. Jerry HirschMcGraw-Hill (Behavior-genetic analysis).

Millot, J.

1926. Contribution à l' histophysiologie des Aranéides. Bull. Biol. Fr. et Belg., Supp. $8: 1-238$.

Peakall, D. B.

1964. Composition, function and glandular origin of the silk fibroions of the spider Araneus diadematus Cl. J. Exp. Zool., 156: 345-350.

1969. Silk synthesis, mechanism and location. Amer. Zoologist, 9: 71-79.

Peters, H. M.

1939. Über das Kreuzspinnennetz und seine Probleme. Naturwissenschaften $47: 776-786$.

Pöтzsch, J.

1963. Von der Brutfürsorge heimischer Spinnen. Wittenberg, Ziemsen.

ReEd, C. F. ANd WitT, P. N.

1972. Growth rate and longevity in two species of orb-weavers. Bull. Brit. Archnol. Soc. 2 (6) : 111-112. 
Reed, C. F., WitT, P. N. ANd Jones, R. L.

1965. The measuring function of the first legs of Araneus diadematus Cl. Behavior 25: 98-119.

Reed, C. F., Witt, P. N. and Scarboro, M. B.

1969. The orb web during the life of Argiope aurantia (Lucas). Devel. Psychobiology 2(2): 120-129.

Reed, C. F., Witt, P. N., Scarboro, M. B. and Peakall, D. B.

1970. Experience and the orb- web. Devel. Psychobiology 3 (4): 251-265.

SEKIGUCHI, K.

1955. Differences in the spinning organs between male and female spiders. Sci. Rep. Tokyo Kyoiku Daigaku, 8: 23-32.

TERMEYER, R. M. DE

1791. Richerche e sperimenti sulla seta dei Ragni e sulla loro generazioni. Scelte d'opusculi interessanti 3: 288.

TURnBull, A. L.

1962. Quantitative studies of the food of Linyphia triangularis Cl.

White, C. (Aranea: Linyphiidae). Canad. Entomologist, 94(12) : 1233-1249.

1952. The use of ranks in test significance for comparing two treatments. Biometrics, 8: 33-41.

WieHLe, J.

1927. Beitrãge zur Kenntnis des Radnetzbaues der Epeiriden, Tetragnathiden and Uloboriden. $Z$. Morpholog. u. Okolog. der Tiere, 8 : 468-537.

WolfF, D. and Hempel, U.

1951. Versuche über die Beeinflussung des Netzbaues von Zilla-xnotata durch Pervitin, Scopolamin and Strychnin. $Z$. vergl. Physiol., 33 : 497-528.

WITT, P. N.

1963a. Interrelationships between web-building behavior and amount of thread material in the spider Araneus diadematus Cl. Proceed. of XVI Intern. Cong. of Zool.

1963b. Environment in relation to behavior of spiders. Arch of environ. Hlth., 7: 4-12.

WitT, P. N. AND Reed, C. F.

1965. Spider web-building. Measurements of web geometry identifies components in a complex invertebrate behavior pattern. Science, 149: 1190-1197.

Witt, P. N., Reed, C. F. and Peakall, D. B.

1968. A spider's web. Problems in regulatory biology. Springer-Verlag, New York.

Witt, P. N., Rawlings, J. O. and Reed, C. F.

1972. Ontogeny of web building behavior in two orb-weaving spiders. Am. Zoologist 12: 445-454. 

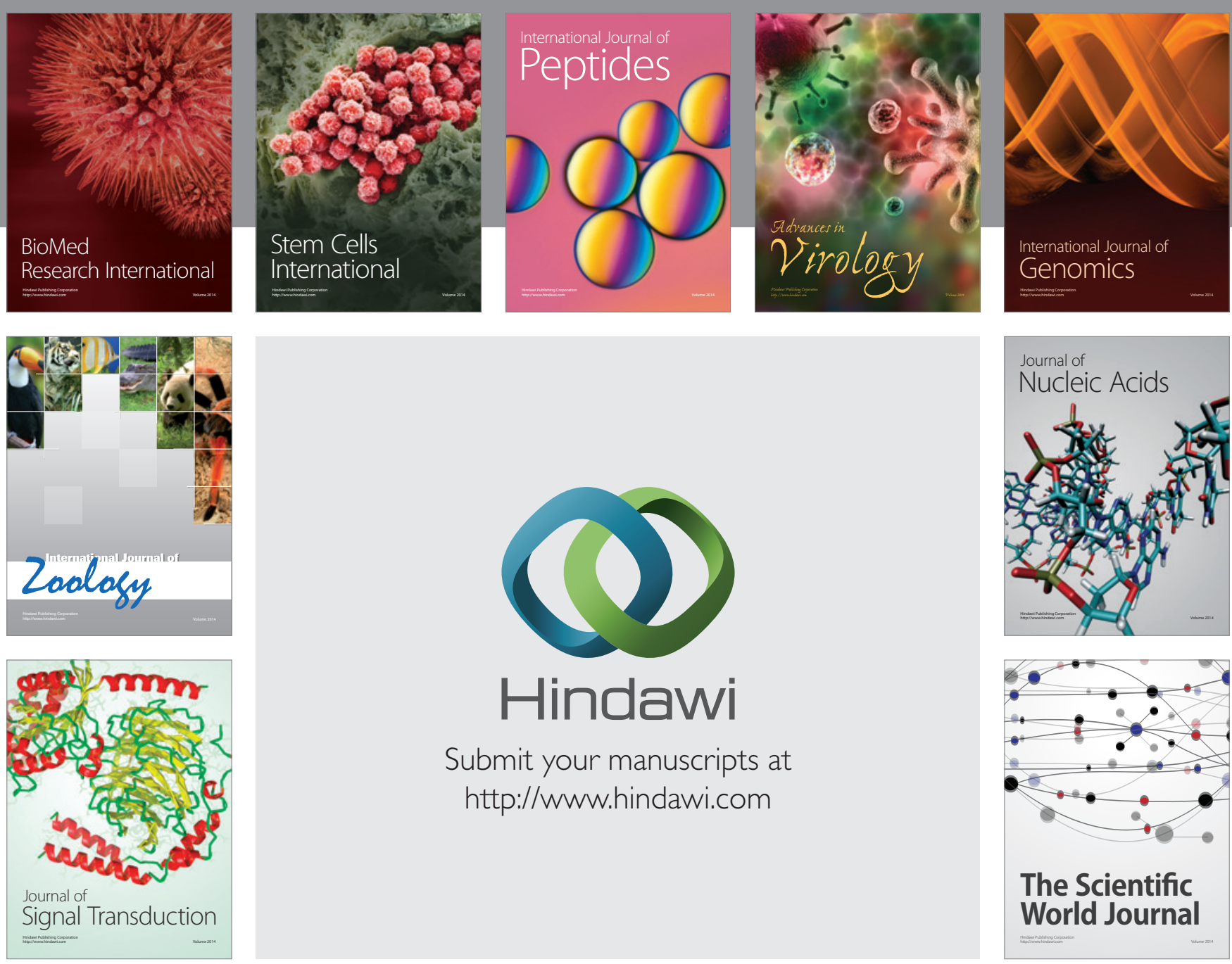

Submit your manuscripts at

http://www.hindawi.com
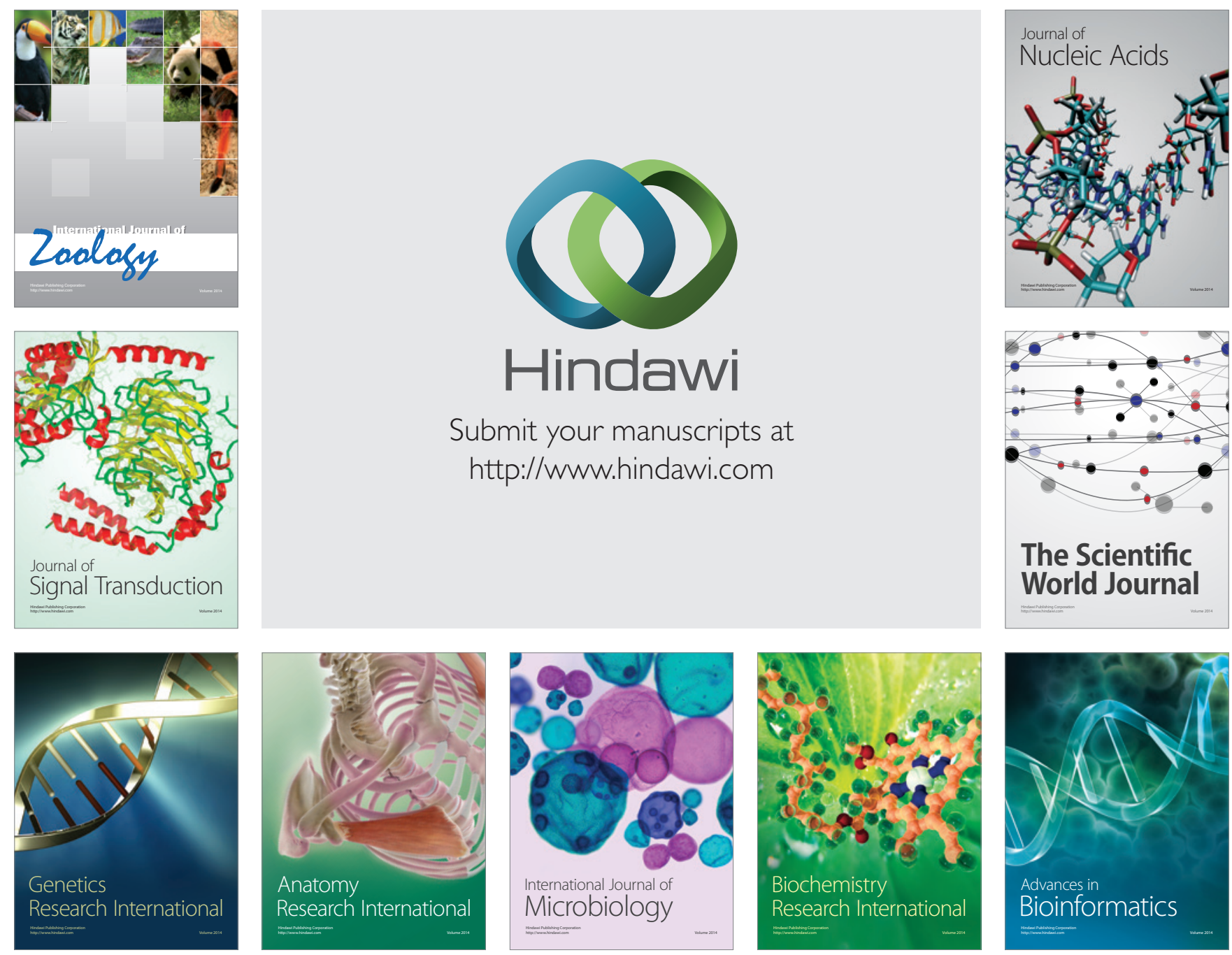

The Scientific World Journal
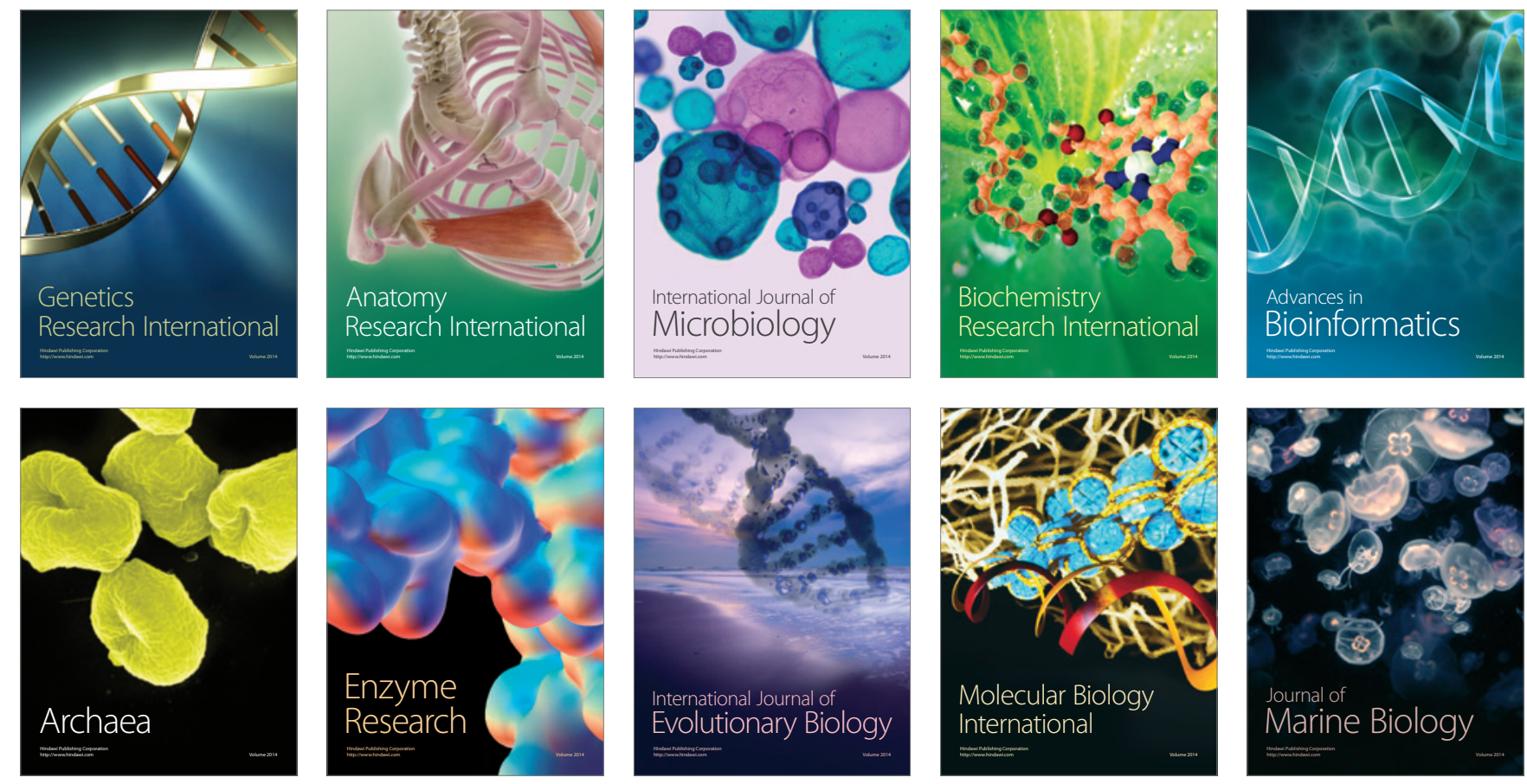